DOI: $10.17516 / 1997-1370-0864$

УДК 330.322

\title{
Application of the Project Approach in the Territorial Development of the Eastern Regions of Russia
}

\author{
Galina I. Popodko*a,b, Olga S. Nagaevaa, \\ and Eugenia B. Bukharova ${ }^{a}$ \\ a Siberian Federal University \\ Krasnoyarsk, Russian Federation \\ ${ }^{b}$ Institute of Economics and Industrial Engineering \\ of the Siberian Branch of the RAS \\ Novosibirsk, Russian Federation
}

Received 01.07.2021, received in revised form 05.11.2021, accepted 10.11.2021

\begin{abstract}
Natural resources extraction, industrial and social development of the Eastern regions of Russia is associated with great costs and takes a long time. These costs are due to both natural and climatic conditions, and poor-developed infrastructure of the territory. Use of the project approach may accelerate regional development. The project approach assumes the achievement of goals in a short-time period and the use of various investment sources. The Krasnoyarsk Krai applies the project approach for natural resources extraction and industrial development. In the region, large-scale investment projects have been implemented for 20 years. These projects have huge socio-economic effects. The Krasnoyarsk Krai has unique features that make it possible to implement large-scale investment projects based on the principle of public-private partnership, where private investments make up the bulk of the total investment.

The regional advantages are its geographical position; huge reserves of hydrocarbons, coal, gold and other minerals; involvement in natural resources development of large companies and investors, such as MMC Norilsk Nickel, Rosneft Oil Company, Rusal, Sberbank and others. Significant industrial and scientific potential also contributes to the successful implementation of large-scale investment projects in Krasnoyarsk Region. The purpose of the study is to assess the socio-economic effects of large-scale investment projects implemented in the Krasnoyarsk Krai. The paper analyzes investment projects for the integrated development of the Lower Angara region, the Arctic zone of the Krasnoyarsk Krai and «Yenisei Siberia». The results demonstrate that projects of natural resource use result in the infrastructure development, new jobs creation, an increase in tax revenues, and the acceleration of economic growth. The paper also identifies problems, bottlenecks and risks of the investment projects, which enables the planning and economic authorities of the region to correct investment decisions and prevent negative social, economic and environmental consequences.
\end{abstract}

\footnotetext{
(C) Siberian Federal University. All rights reserved

* Corresponding author E-mail address: pgi90@bk.ru

ORCID: 0000-0003-0529-7010 (Popodko); 0000-0003-3946-3144 (Nagaeva); 0000-0002-5198-8894 (Bukharova)
} 
Keywords: project approach, territorial development, investment projects, Eastern regions of Russia, Krasnoyarsk Krai, Lower Angara region, Arctic zone, Yenisei Siberia project, effect.

The work was carried out within the framework of the project «The role of planning government bodies in the socio-economic development of the Krasnoyarsk Territory (economic and historical aspect)», supported by the Krasnoyarsk Regional Fund for the support of scientific and scientific and technical activities (application No. 2020020605932).

Research area: economics.

Citation: Popodko, G.I., Nagaeva, O.S., Bukharova, E.B. (2021). Application of the project approach in the territorial development of the eastern regions of Russia. J. Sib. Fed. Univ. Humanit. soc. sci., 14(12), 1851-1862. DOI: 10.17516/1997-1370-0864

\title{
Применение проектного подхода в территориальном развитии восточных регионов России
}

\author{
Г.И. Поподько, б, О.С. Нагаеваа,, Е.Б. Бухарова ${ }^{a}$ \\ ${ }^{a}$ Сибирский федеральный университет \\ Российская Федерачия, Красноярск \\ ${ }^{6}$ Институт экономики \\ и организации промышленного производства СО РАН \\ Российская Федерачия, Новосибирск
}

\begin{abstract}
Аннотация. Освоение природных запасов, промышленное и социальное развитие восточных регионов страны требуют колоссальных затрат и длительного времени. Это вызвано как суровыми природно-климатическими условиями, так и слабой освоенностью территории. Ускорение в развитии регионов может придать применение проектного подхода, позволяющего реализовать намеченные цели в короткие сроки с привлечением различных источников инвестирования. Наглядным примером реализации проектного подхода в освоении природных богатств и промышленном развитии региона является Красноярский край, на территории которого в течение более 20 лет реализуются мегапроекты, дающие значимые социально-экономические эффекты. Красноярский край, едва ли не единственный регион в России, обладает уникальными особенностями, позволяющими реализовать крупные инвестиционные проекты народно-хозяйственного значения на основе принципа частно-государственного партнерства, когда частные инвестиции составляют большую часть всего объема инвестирования. К преимуществам региона можно отнести: удобное географическое положение; огромные запасы углеводородного сырья, угля, золота и других полезных ископаемых; вовлеченность в процесс освоения природных ресурсов региона крупных компаний и инвесторов страны, таких как ПАО «ГМК «Норильский никель», Роснефть, АО «Полюс Красноярск», АО РУСАЛ, Сбербанк и др. Успешной реализации крупных инвестиционных
\end{abstract}


проектов способствует и то, что Красноярский край обладает значительным промышленным и научным потенциалом. Целью исследования является оценка социально-экономического эффекта реализации инвестиционных мегапроектов на территории Красноярского края с участием крупных частных инвесторов. Анализ реализации проектов комплексного освоения Нижнего Приангарья, Арктической зоны Красноярского края и Енисейской Сибири показывает, что добыча природных запасов региона в рамках названных проектов приводит к активизации социально-экономического развития Красноярского края, снятию инфраструктурных ограничений и ускорению экономического роста, увеличению налоговых поступлений в бюджеты всех уровней и созданию новых рабочих мест. Вместе с тем проведенный анализ реализации крупных инвестиционных проектов на территории Красноярского края позволяет не только оценить синергетический экономический и социальный эффекты, но и выявить проблемы, узкие места и риски, что дает возможность планово-экономическим органам региона скорректировать решения и предотвратить наступление негативных социальных, экономических и экологических последствий.

Ключевые слова: проектный подход, территориальное развитие, инвестиционные проекты, восточные регионы России, Красноярский край, Нижнее Приангарье, Арктическая зона, Енисейская Сибирь, эффект.

Работа выполнена в рамках реализации проекта «Роль плановых органов государственного управления в социально-экономическом развитии Красноярского края (экономико-исторический аспект)», поддержанного Красноярским краевым фондом поддержки научной и научно-технической деятельности (заявка № 2020020605932).

Научная специальность: 08.00.00 - экономические науки.

\section{Введение}

Масштабное освоение территории восточных регионов страны, большинство из которых характеризуются как ресурсные, обусловлено необходимостью обеспечения промышленного и социального развития с целью создания благоприятных условий жизни для населения. Это требует огромных инвестиционных затрат (Chatzitheodorou, Skouloudis, Evangelinos, Nikolaou, 2019). Реализация проектов развития регионов только с участием государственных инвестиций ограничена отсутствием необходимых средств и может быть растянута на долгие годы (Miranda, Tereso, Teixeira, 2021). Вместе с тем использование проектного подхода, наряду с привлечением частных инвестиций в территориальном развитии, дает огромный социально-экономический эффект.
Проектное освоение территории Красноярского края намечалось задолго до современного периода. Уже в 20-30-е годы прошлого столетия правительством СССР разрабатывались планы использования гидроресурсов Нижнего Пиангарья как источника дешевой электроэнергии. К этому времени было уже известно о наличии здесь больших запасов полезных ископаемых: $13 \%$ золота, $6,4 \%$ леса, $6 \%$ нефти и газа, $31 \%$ свинца, 30 \% талька, $2 \%$ железа, 15 \% марганца от общероссийских запасов (Zona operezhayushchego razvitiya, 2015).

В настоящее время объемы разведанных полезных ископаемых заметно выросли. Красноярский край занимает одно из ведущих мест в России по запасам минеральных ресурсов и полезных ископаемых, из которых ведущими являются (в скобках доля от общероссийских запасов): алмазы импактные (100 \%), плати- 
ноиды (96,86 \%), уголь (77,6 \%), никель $(71,7 \%)$, кобальт $(55,0 \%)$, медь $(33,8 \%)$, свинец $(25,8 \%)$, золото (14,4\%), серебро $(16 \%)$, сурьма $(15,4 \%)$, марганец $(11,4 \%)$, нефелиновые руды $(10,91 \%)$, оптический кальцит (96,8 \%), графит (34,74\%), магнезит $(25,6 \%)$, асбест $(6,6 \%)$. (Spravka o sostoyanii, 2019).

Основные препятствия в освоении природных богатств Красноярского края труднодоступность территории залегания природных запасов; суровые природноклиматические условия, слабая освоенность территории; неразвитая транспортная и производственная инфраструктура; нехватка высококвалифицированных кадров, что обуславливает необходимость привлечения специалистов на основе вахтового метода. Для освоения природных ресурсов и развития территорий широко применяется частно-государственное партнерство, при котором освоение месторождений, строительство крупных инфраструктурных объектов и производственных комплексов осуществляются за счет привлечения частных инвестиций отечественных и зарубежных компаний при непосредственном участии государства и региона путем реализации крупных инвестиционных проектов (Liu, Marshall, McColgan, 2021). Преимуществом такого подхода служит, во-первых, своевременное финансирование в достаточном объеме; во-вторых, ускоренное строительство производственных и инфраструктурных объектов; в-третьих, использование передовых производственных технологий и инноваций; в-четвертых, возможность осуществления контроля за состоянием экологии при разработке месторождений и строительстве производственных объектов со стороны государственных органов (Rasmussen, Fold, Olesen, Shackleton, 2021).

Целью настоящего исследования является оценка социально-экономического эффекта реализации инвестиционных мегапроектов на территории Красноярского края с участием крупных частных инвесторов.

\section{Данные и методы исследования}

Для получения данных о реализации инвестиционных мегапроектов на территории Красноярского края использована информация из оперативных источников (нормативные документы, справки, прессрелизы, данные с сайтов администрации Красноярского края), статистических сборников, докладов руководителей региона. Полученная информация была обработана методами статистического анализа и экспертных оценок.

Самым первым крупным инвестиционным проектом, реализованным на территории Красноярского края, является мегапроект «Комплексное освоение Нижнего Приангарья». История освоения Нижнего Приангарья началась еще в дореволюционной России, затем к этой теме вернулись в 20-е гг. прошлого столетия, но помешала война. Начало реализации проекта следует отнести к 1980 г., когда было принято решение о строительстве Богучанской ГЭС, первые агрегаты которой должны были дать ток в 1998 г. Однако планы ввода ГЭС были сорваны, а стройка остановлена. Фактическая реализация проекта началась в 2006 г., когда по инициативе губернатора Красноярского края А.Г. Хлопонина был разработан проект «Комплексное развитие Нижнего Приангарья», предусматривающий создание на основе принципов государственночастного партнерства условий для формирования на территории Красноярского края нового крупного промышленного района, основанного на использовании богатейшего природно-ресурсного потенциала Нижнего Приангарья, электроэнергии Богучанской ГЭС и развитии транспортной инфраструктуры. Проект получил государственную поддержку из Инвестиционного фонда Российской Федерации. Это был первый в стране крупный проект, реализация которого осуществлялась на основе привлечения частных инвестиций.

Целью комплексного инвестиционного проекта было укрепление промышленного потенциала территорий на востоке страны (Нижнее Приангарье). Развитие Нижнего Приангарья реализовывалось в два эта- 
па: первый - 2006-2010 гг., второй - 20112015 гг. На первом этапе предполагался запуск ряда ключевых промышленных объектов. В их число входили: Богучанская ГЭС (70,4 млрд руб.), алюминиевый завод неподалеку от пос. Карабула (67,9 млрд руб.), Богучанский лесопромышленный комплекс производительностью 800 тыс. т целлюлозы в год (41,4 млрд руб.). К инфраструктурным объектам первой очереди относились: мостовой переход через реку Ангару, автодорога Канск-Абан-БогучаныКодинск, линии электропередач, участок железной дороги Карабула-Ярки (Pasport kompleksnogo investicionnogo proekta, 2010).

Строительство Богучанской ГЭС и алюминиевого завода осуществлялось в соответствии с Соглашением о сотрудничестве между ОАО «Русский алюминий» и ОАО «ГидроОГК» в рамках совместного проекта «Богучанское энергометаллургическое объединение» (БЭМО). Возведение лесопромышленного комплекса взял на себя Внешэкономбанк, договорившись о совместном инвестировании с ОАО «Корпорация развития Красноярского края» (Ionova, Malov, 2007).

На втором этапе реализации проекта предполагалось строительство Тагарского металлургического объединения. Намечаемый срок реализации проекта - 20062015 гг. В действительности строительство некоторых объектов продолжается и сейчас. Окупаемость проекта - 20 лет.

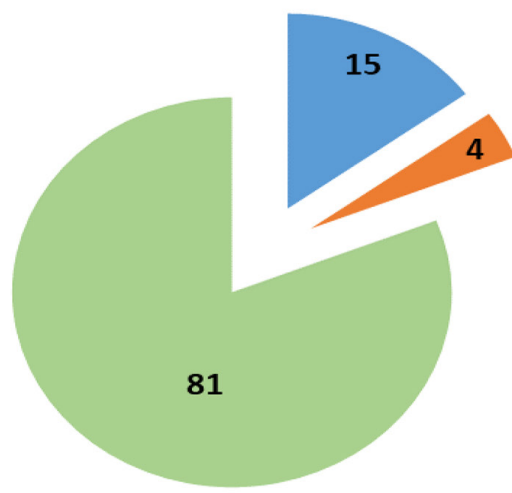

Общий объем инвестиций по проекту составил более 222 млрд руб., из них:

- Инвестиционный фонд РФ 34223 млн руб.;

- федеральный бюджет (ФАИП) 8800 млн руб.;

- собственные и заемные средства инвесторов - 179600 млн руб.

Структура инвестиций в проект «Комплексное освоение Нижнего Приангарья» представлена на рис. 1.

С учетом масштабов проекта «Комплексное освоение Нижнего Приангарья» его реализация не закончилась вводом в эксплуатацию Богучанской ГЭС (проектная мощность была достигнута в 2015 г., а полное завершение - в 2017 г.), строительством Богучанского алюминиевого завода, завершением строительства ряда инфраструктурных объектов, а продолжается в виде комплексного инвестиционного проекта «Ангаро-Енисейский кластер» (Angaro-Enisejskij klaster, 2012).

Решение о вхождении в Красноярский край Таймырского (Долгано-Ненецкого) и Эвенкийского автономных округов в 2007 г. открыло новые возможности в освоении Арктической зоны региона. Актический Север представляется как территория перспективного развития (Eliasson, Ulfarsson, Valsson, Gardarsson, 2017). Арктическая зона края составляет около 10100 тыс. км², численность населения, проживающего в Арктике, не превышает

Рис. 1. Структура инвестиций в проект «Комплексное развитие Нижнего Приангарья», \%

Fig. 1. Structure of investments in the project «Integrated development of the Lower Angara region», \% 
230 тыс. чел. (8 \% от численности населения Красноярского края). Но при этом здесь имеются крупнейшие в мире запасы нефти (Fry, Hilburn, 2020).

Проекты Арктической зоны Красноярского края включают как освоение крупных месторождений полезных ископаемых, так и промышленное развитие территории Арктики. И здесь крайне важен выбор проектов освоения Арктической зоны (Novoselov, Potravny, Novoselova, Gassiy, 2017).

Перспективы развития Арктической зоны Красноярского края связаны с реализацией следующих направлений:

1) дальнейшее развитие металлургии в Норильском промышленном районе;

2) освоение новых месторождений Ванкорского кластера (Сузунского, Лодочного, Тагульского);

3) формирование новых центров добычи нефти и угля.

Начало реализации проектов развития «Норникеля» - 2019 г. Инвестором является ПАО «ГМК «Норильский никель» («Nornikel'» nachinaet realizaciyu perspektivnyh proektov, 2019).

ПАО «ГМК «Норильский никель», крупнейший в мире производитель палладия и рафинированного никеля, в 2019 г. принял инвестиционные решения о реализации перспективных проектов роста по расширению и реконструкции Талнахской обогатительной фабрики и развитию Южного кластера. Суммарные инвестиции в них составят до 90 млрд руб. в ближайшие четыре года, ожидаемый итог - существенное увеличение производства цветных металлов и металлов платиновой группы.

«Южный кластер» - это проект «Норникеля» по освоению запасов северной части месторождения «Норильск-1», месторождения, с которого началась история компании. Проект дает в значительной степени выработанному месторождению «вторую» жизнь.

Объем запасов вкрапленных руд составляет 165 млн т. В результате его реализации в 2027 г. суммарные добывающие мощности достигнут 9 млн т. Благодаря использованию имеющейся инфраструк- туры, вскрышные работы начались уже в 2019 г., а первая добыча ожидается в 2021-2022 гг. На первом этапе реализации проекта основной рост добычи предусматривается за счет расширения карьера (открытым способом), а на втором - за счет подземной выработки. По предварительной оценке инвестиции в развитие горной добычи Южного кластера составят более 45 млрд руб.

Крупнейший проект по освоению запасов углеводородного сырья Арктического Севера - проект «Восток-Ойл». Начало его реализации - 2020 г. Инвестор - компания «Роснефть» (Tajmyrskij proryv: «Vostok Ojl», 2020).

Общие ресурсы месторождения нефти оцениваются в 5 млрд т нефти или 37 млрд баррелей нефтяного эквивалента. Запуск проекта намечен на 2024 г. Объем инвестиций составляет 2,33 трлн руб.

Для реализации проекта «Восток Ойл» на Таймыре построят 15 промысловых городков, два новых аэродрома и морской порт. Из Туруханского района на север будет проложен 800-километровый магистральный трубопровод, несколько тысяч километров электрических сетей и две тысячи мегаватт генерации. Запланированный нефтегазовый прорыв тесно связан с развитием Северного морского пути. Именно углеводороды должны обеспечить его стабильную плановую загрузку - около 50 млн т нефти в год на первом этапе и до 100 млн т - на втором.

В 2020 г. началась реализация проекта создания угольного кластера на Таймыре. Инвестор - компания «Северная звезда», дочерняя структура «Норильского никеля» (Syradasajskoe mestorozhdeniel, 2020). Масштабный проект включен в стратегию социально-экономического развития Арктического региона и в планы по увеличению грузопотока Северного морского пути до 80 млн т в год (Kamenopoulos, Agioutantis, 2021).

Участие региональных органов в освоении Арктической зоны выражается в создании благоприятных налоговых условий для компаний, занятых освоением нефтя- 
ных месторождений и строительством производственных объектов. В конце 2020 г. принят региональный закон, устанавливающий пониженные ставки по налогу на прибыль и налогу на имущество. Ставки налога на прибыль приняты на уровнях: 0,5\% на 2026-2030 гг. и 2, 5 \% на 2031-2036 гг. (Zakon Krasnoyarskogo kraya ot 19.11.2020 № 10-4347).

Несмотря на то, что проекты «Комплексного развития Нижнего Приангарья» и «Освоение Арктической зоны» являются крупнейшими инвестиционными проектами, самым масштабным мегапроектом, реализуемым на территории Красноярского края (и России), признан комплексный инвестиционный проект (КИП) «Енисейская Сибирь».

Проект охватывает территории трех регионов - Красноярский край, Республика Хакасия и Республика Тыва с возможным расширением числа участников. Реализация проекта «Енисейская Сибирь» значима не только для развития названных регионов, но и для страны в целом.

Непосредственно на территории Красноярского края будут реализованы 12 крупных проектов по строительству инфраструктурных и производственных объектов (Rasporyazhenie Gubernatora Krasnoyarskogo kraya ot 29.12.2018 № 730).

Цель комплексного инвестиционного проекта - активизация социальноэкономического развития Красноярского края, снятие инфраструктурных ограничений и ускорение экономического роста, рост налоговых поступлений в бюджеты всех уровней, создание новых рабочих мест и рост реальных денежных доходов населения Красноярского края.

Срок реализации мегапроекта - 20182027 гг. Участниками проекта, помимо Администрации Красноярского края, являются более 30 компаний, среди которых $\mathrm{AO}$ «Норильский никель», объединенная компания «РУСАЛ», АО «Полюс Красноярск» и др. Стоимость инвестиционного проекта КИП «Енисейская Сибирь», реализуемого на территории Красноярского края, оценивается в 1253,83 млрд руб.
Среди утвержденного перечня проектов, реализуемых в рамках КИП «Енисейская Сибирь», следует выделить семь наиболее важных (Sem' glavnyh proektov «Enisejskoj Sibiri», 2019):

1. Проект «Южный кластер».

Проект «ГМК «Норильский никель» предусматривает освоение северной части месторождения «Норильск-1», развитие рудника «Заполярный», карьера «Медвежий ручей», комплексную реконструкцию Норильской обогатительной фабрики. Инвестиции в развитие горной добычи и модернизацию хвостового хозяйства составят около 70 млрд руб. Затраты на модернизацию Норильской обогатительной фабрики оцениваются в 40 млрд руб.

2. Проект развития инфраструктуры и освоения ресурсной базы АнгароЕнисейского экономического района.

Проект предполагает строительство моста через Енисей в районе поселка Высокогорский в Енисейском районе Красноярского края. Развитие транспортной инфраструктуры необходимо в том числе для наращивания золотодобычи.

3. Проект «Технологическая долина».

Это совместный проект правительства Красноярского края, Алюминиевой ассоциации и компании «Русал». Его цель - создание комплекса предприятий по выпуску алюминиевой продукции высокого передела в Красноярске и Хакасии, в непосредственной близости от Красноярского алюминиевого завода, Красноярского металлургического завода и Красноярской ГЭС.

4. Проект «Международный транспортно-логистический хаб».

Проект предполагает создание в Красноярке крупнейшего в России международного логистического хаба и включает в себя строительство складских комплексов и сортировочного центра, запуск мультимодальных моделей перевозок, создание предприятий, ориентированных на выпуск продукции с высокой добавленной стоимостью. Проект будет развиваться в формате особой экономической зоны. 
5. Проект «Модернизация энергомощностей и оптимизация системы теплоснабжения города Красноярска».

Проект предполагает обновление действующих предприятий «Сибирской генерирующей компании», в частности комплексную модернизацию Красноярской ТЭЦ-1 и расширение Красноярской ТЭЦ-3, а также замещение малых котельных.

6. Проект «Агропромышленный парк «Сибирь».

Проект предполагает развитие в Шарыповском районе большого тепличного комлекса, предприятий глубокой переработки зерна, птицефабрики и рыбной фермы. Реализуется ПАО «Юнипро» с 2016 г. с использованием инфраструктуры Березовской ГРЭС.

7. Проект «Строительство железной дороги Элегест-Кызыл-Курагино и освоение минерально-сырьевой базы Республики Тыва».

Проект включает три составляющие: строительство железной дороги протяженностью 410 км, горно-обогатительного комбината на Элегестском месторождении угля и угольного портового терминала в Хабаровском крае.

\section{Результаты исследования}

Для оценки эффекта от реализации мегапроектов на территории Красноярского края анализируется:

- число реализуемых проектов в рамках мегапроекта;

- объем инвестиций;

- участие частных компаний в реализации проектов;

- количество новых рабочих мест;

- рост доходов бюджета региона.

Эффект от реализации проекта «Комплексное развитие Нижнего Приангарья» состоит в следующем:

1) ликвидация дефицита электрической мощности путем строительства и ввода в эксплуатацию новой Нижнеангарской ГЭС мощностью 1082 МВт;

2) обеспечение транспортной доступности правобережья Ангары и Енисея, а также юга Саянского района путем стро- ительства мостового перехода через Енисей, реконструкции и нового строительства 642,1 км автомобильных дорог с твердым покрытием;

3) увеличение добычи золота на 14,1 т в год (на 34 \% по краю), никеля на 45,1 тыс. т в год (на $36 \%$ по краю);

4) увеличение производство периклазовых порошков на 100 тыс. т в год (в 8 раз по краю), производство пиломатериалов на 157 тыс. куб. м в год (на 8 \% по краю);

5) увеличение выработки электроэнергии на 7,3 млрд кВт*ч в год;

6) организация и сохранение 6,5 тыс. новых постоянных рабочих мест;

7) увеличение суммарного объема налоговых отчислений в консолидированный бюджет Красноярского края на 12,6 млрд руб. ежегодно.

Однако отсутствие положительного опыта реализации столь глобальных проектов в РФ и в Красноярском крае ожидаемо повлекло за собой ошибки и просчеты.

Во-первых, в проекте предусмотрено недостаточное количество транспортной и энергетической инфраструктуры. Такое положение ставит под сомнение эффективность реализации проекта (Lairda, Venables, 2017). В первую очередь, это относится к отсутствию в утвержденной программе проекта строительства участка СевероСибирской магистрали Усть-Илимск - Лесосибирск, проходящей по правому берегу Ангары. Такое положение ставит под сомнение возможность освоения месторождений и строительства перерабатывающих предприятий, таких как Тагарское металлургическое объединение, Порожский ГОК и др. (Ionova, Malov, 2007).

Во-вторых, нереальными оказались сроки строительства крупных промышленных предприятий. Это касается, прежде всего, создания ЛПК, ввод которого должен был быть осуществлен еще в 2010 г. После нескольких попыток реализации проекта выяснилось, что проект Богучанского ЦБК не прошел госэкпертизы и не пригоден к реализации из-за ряда серьезных ошибок при проектировании. В результате масштабы создаваемых предприятий измени- 
лись и решено было построить только цех по производству пиломатериалов.

В-третьих, отсутствие комплексного подхода в развитии Нижнего Приангарья. Регион развивается преимущественно по сырьевому сценарию. Согласно утвержденному проекту, ускоренное развитие получают только два промышленных узла - Богучанский и Кодинский. Промышленное и социальное освоение всей территории выходит далеко за пределы 2030 г. (Burmatova,2018).

В-четвертых, экологические «пробелы» в реализации комплексного проекта. Большинство проектов, реализуемых в рамках комплексного освоения Нижнего Приангарья, не прошли достаточно проработанной экологической экспертизы и наносят экологический вред (Vorob'eva, Esikova, Ionova, Malov, 2007).

Характеризуя инвестиционный проект «Комплексное развитие Нижнего Приангарья» в целом, следует отметить, что в нем отсутствуют такие важные признаки, как комплексность развития территории с позиций формирования и функционирования базовых отраслей его экономики во взаимосвязи с социальной сферой и окружающей средой; координация создания и функционирования всех объектов на территории; формирование инфраструктуры местного значения; учет требований охраны окружающей среды и воспроизводства природных ресурсов; решение социальных проблем, нацеленных на повышение уровня жизни людей; возможность использовать имеющиеся природные ресурсы в интересах не только крупных компаний, но и проживающего в регионе населения и др.

Реализация проектов освоения Арктической зоны Красноярского края имеет огромный экономический и социальный эффект. Примерное число будущих рабочих мест более ста тысяч. Это позволит ежегодно увеличить ВВП страны на два процента. Запланированный нефтегазовый прорыв тесно связан с развитием Северного морского пути (Bardal, 2020). По расчетам ученых РАН, дополнительный рост ВРП Красноярского края в результате реализа- ции только проекта «Восток-Ойл» составит примерно 252 млрд руб.

Общий социально-экономический эффект от реализации КИП «Енисейская Сибирь» на территории Красноярского края оценивается следующим образом:

- $\quad$ 70,5 тыс. новых рабочих мест;

- 528 млрд руб. налоговых отчислений;

- 250 \% увеличения оборота субъектов МСП; стиций

- рост прямых иностранных инве-

- прирост населения Енисейской Сибири;

- удвоение индекса развития человеческого потенциала.

Научный и практический интерес представляет сравнение мегапроектов Красноярского края. Это позволит не только оценить их масштабы, но и выявить специфические особенности, которые должны приниматься во внимание региональными плановыми органами, осуществляющими мониторинг и контроль за их выполнением.

Комплексная оценка мегапроектов, реализуемых на территории Красноярского края, представлена в табл. 1.

Как показывает сравнение мегапроектов Красноярского края, самым продолжительным по времени реализации является проект «Комплексное освоение Нижнего Приангарья» (более 20 лет), наиболее затратным - проекты освоения Арктической зоны $(63 \%$ всего объема инвестиций, выделенных на мегапроекты), наибольший вклад в доход регионального бюджета ожидается от КИП «Енисейская Сибирь» (73 \% прироста дохода бюджета от реализации инвестиционных проектов).

\section{Заключение}

Как показывает оценка эффективности реализации мегапроектов на территории Красноярского края, они значительно влияют на рост уровня социально-экономического развития региона. Большинство из названных проектов реализуются в труднодоступных районах в условиях неблагоприятного сурово- 
Таблица 1. Комплексная оценка мегапроектов, реализуемых в Красноярском крае Table 1. Comprehensive assessment of large-scale investment projects implemented in Krasnoyarsk Region

\begin{tabular}{|c|c|c|c|c|}
\hline Направление & $\begin{array}{c}\text { Комплексное } \\
\text { развитие Нижнего } \\
\text { Приангарья }\end{array}$ & $\begin{array}{c}\text { Освоение } \\
\text { Арктической зоны }\end{array}$ & $\begin{array}{c}\text { КИП «Енисейская } \\
\text { Сибирь» }\end{array}$ & Итог \\
\hline $\begin{array}{l}\text { Сроки реализации, } \\
\text { лет }\end{array}$ & $2006-2025$ & 2019-2036 & 2018-2027 & 2006-2036 \\
\hline $\begin{array}{l}\text { Число реализуемых } \\
\text { проектов, } \\
\text { количество }\end{array}$ & 8 & 5 & 12 & 25 \\
\hline $\begin{array}{l}\text { Объем инвестиций, } \\
\text { млрд руб. }\end{array}$ & 222 & 2475 & 1253,8 & 3910,8 \\
\hline $\begin{array}{l}\text { Компании-участники } \\
\text { проектов }\end{array}$ & $\begin{array}{c}\text { ОАО «Русский } \\
\text { алюминий», ОАО } \\
\text { «ГидроОГК», } \\
\text { Внешэконом } \\
\text { банк }\end{array}$ & $\begin{array}{c}\text { ПАО «ГМК } \\
\text { «Норильский } \\
\text { никель», } \\
\text { «Роснефть», } \\
\text { «Северная звезда», } \\
\text { Сбербанк }\end{array}$ & $\begin{array}{c}30 \text { компаний, среди } \\
\text { которых ПАО } \\
\text { «Норильский никель», } \\
\text { объединенная компания } \\
\text { «РУСАЛ», АО «Полюс } \\
\text { Красноярск» и др. }\end{array}$ & \\
\hline $\begin{array}{l}\text { Количество } \\
\text { создаваемых } \\
\text { рабочих, тыс. мест }\end{array}$ & 6,5 & 100 & 70,5 & 177 \\
\hline $\begin{array}{l}\text { Отчисления } \\
\text { в региональный } \\
\text { бюджет, млрд руб. }\end{array}$ & 12,6 ежегодно & 6,3 ежегодно & 52,8 ежегодно & $\begin{array}{c}71,6 \\
\text { ежегодно }\end{array}$ \\
\hline
\end{tabular}

Источник: Составлено авторами.

го климата. Это сказывается на высоких затратах, связанных со строительством транспортной и логистической инфраструктуры, социальным и промышленным освоением территории. Такое положение всегда рассматривалось как ограничение в развитии Красноярского края. Решением этой проблемы является привлечение инвестиций крупных частных компаний, таких как РУСАЛ, «Норильский никель», «Роснефть», «Полюс золото» и других компаний. Так, благодаря реализации инвестиционных проектов в Нижнем Приангарье, во-первых, ликвидирован дефицит электроэнергии, что позволило запустить ряд крупных промышленных предприятий; во-вторых, обеспечена транспортная доступность правобережья Ангары и Енисея; в-третьих, увеличилась добыча золота и других полезных ископаемых. Реализация проектов освоения Арктического Севера приведет к промышленному освоению и развитию транспортной и энергетической инфраструктуры на данной территории. Это, в свою очередь, обеспечит загруженность Северного морского пути. Комплексный инвестиционный проект «Енисейская Сибирь», направленный на ускорение экономического и социального развития региона, обеспечит строительство крупных инфраструктурных объектов, создание промышленных кластеров, рост налоговых поступлений в краевой бюджет. Его реализация направлена на интеграцию и кооперацию межрегиональных связей с другими регионами, обладающими большими производственным и сырьевым потенциалами. 


\section{Список литературы / References}

Angaro-Enisejskij klaster dlya kitajskih bolvanchikov? [Angara-Yenisei cluster for Chinese dummies?] (2012). Available at: http://npriangarie.ru/2012/1196 (accessed 14 April 2021)

Bardal, K.G. (2020). Contradictory outcomes of cost-benefit analyses - Findings from Norwegian public-investment project, In Research in Transportation Economics, 4. DOI: 10.1016/j.retrec.2020.100874

Burmatova, O.P. (2018). Strategicheskie razrabotki v rajone novogo osvoeniya [Strategic developments in new settlement regions], In Aktual'nye problemy ekonomiki i prava [Actual Problems of Economics and Law], 12 (2), 221-240. DOI: 10.21202/1993-047X.12.2018.2.221-240

Chatzitheodorou, K., Skouloudis, A., Evangelinos, K., Nikolaou, I. (2019). Exploring socially responsible investment perspectives: A literature mapping and an investor classification. In Sustainable Production and Consumption, 19, 117-129. DOI: 10.1016/j.spc.2019.03.006

Eliasson, K., Ulfarsson, G. F., Valsson, T., Gardarsson, S. M. (2017). Identification of development areas in a warming Arctic with respect to natural resources, transportation, protected areas, and geography. In Futures, 85, 14-27. DOI: 10.1016/j.futures.2016.11.005

Fry, M., Hilburn, A. (2020). The Distributional Justice of Oil Industry Social Development Projects and Oil Field Production Activities. In The Extractive Industries and Society, 7(2), 647-659. DOI: 10.1016/j. exis.2020.03.017

Ionova, V.D., Malov, V. Yu. (2007). Nizhnee Priangar'e: podhody k osvoeniyu i vremya dejstvij (19202020). [The Lower Angara Area: Approaches to Development and Time of Actions (1920-2020)] In Prostranstvennaya ekonomika [Spatial Economics], 3, 21-42. DOI: 10.14530/se.2007.3.021-042

Kamenopoulos, S., Agioutantis, Z. (2021). The Importance of the Social License to Operate at the Investment and Operations Stage of Coal Mining Projects: Application using a Decision Support System. In The Extractive Industries and Society, 8(2), DOI: 10.1016/j.exis.2020.05.019

Lairda, J. J., Venables, A. J. (2017). Transport investment and economic performance: A framework for project appraisal. In Transport Policy, 56, 1-11. DOI: 10.1016/j.tranpol.2017.02.006

Liu, M., Marshall, A., McColgan, P. (2021). Foreign direct investments: The role of corporate social responsibility. In Journal of Multinational Financial Management, 59. DOI: 10.1016/j.mulfin.2020.100663

Miranda, J., Tereso, A., Teixeira, J.C. (2021). Multicriteria analysis as a better tool for the selection of public projects alternatives. In Procedia Computer Science, 181, 545-552. DOI: 10.1016/j.procs.2021.01.201

Novoselov A., Potravny I., Novoselova I. Gassiy V. (2017). Selection of priority investment projects for the development of the Russian Arctic. In Polar Science, 14, 68-77. DOI: 10.1016/j.polar.2017.10.003

«Nornikel'» nachinaet realizaciyu perspektivnyh proektov rosta [«Nornickel» starts implementation of promising projects of growth] (2019). Available at: https://www.nornickel.ru/upload/iblock/700/South_ Cluster_and_TOF_March-2019_rus_full.pdf (accessed 22 April 2021)

Kompleksnoe razvitie Nizhnego Priangar'ya: Pasport kompleksnogo investicionnogo proekta, realizuemogo pri gosudarstvennoj podderzhke za schet sredstv investicionnogo fonda Rossijskoj federacii: [Comprehensive development of the Lower Angara Area: Passport of the investment project implemented with state support at the expense of the investment fund of the Russian Federation] (2007). Available at: http://www.rlw.gov.ru/in_pr_priangar (accessed 13 April 2021)

Rasmussen, L.V., Fold, N., Olesen, R.S., Shackleton, Sh. (2021). Socio-economic outcomes of ecological infrastructure investments. In Ecosystem Services, 47. DOI: 10.1016/j.ecoser.2020.101242

Rasporyazhenie Pravitel'stva RF ot 29 marta 2019 № 571-r [Order of the Government of the Russian Federation dated March 29, 2019 No. 571-r]. Available at: http://publication.pravo.gov.ru/Document/ View/0001201904020008? rangeSize $=50$ (accessed 22. April 2021)

O realizacii kompleksnogo investicionnogo proekta «Enisejskaya Sibir'» na territorii Krasnoyarskogo kraya: Rasporyazhenie Gubernatora Krasnoyarskogo kraya ot 29 dekabrya 2018 g. № 730 - rg [On the implementation of the complex investment project «Yenisei Siberia» on the territory of Krasnoyarsk Krai: Order of the Governor of Krasnoyarsk Krai dated December 29, 2018 No. 730-rg]. Available at: https://docs. cntd.ru/document/550325514 (accessed 27 April 2021) 
Sem' glavnyh proektov «Enisejskoj Sibiri» [Seven main projects of the complex investment project «Yenisei Siberia»] (2018). Available at: https://krasnoyarsk.dk.ru/news/sem-glavnyh-proektov-eniseyskoysibiri-237102587 (accessed 27 April 2021)

Spravka o sostoyanii i perspektivah ispol'zovaniya mineral'no-syr'evoj bazy Krasnoyarskogo kraya (na 15.06.2020 g.) [Information on the state and prospects of using the the mineral resources of Krasnoyarsk Krai (as of June 15, 2020)] (2020). Available at: https://rosnedra.gov.ru/data/Fast/Files/202011/970dbf3b0bdb20ec84431e0e9bc2d58a.pdf (accessed 27 April 2021)

Syradasajskoe mestorozhdenie: Investicionnyj portal Arkticheskoj zony Rossii [Syradasay coal deposit: Investment Portal of the Arctic Zone of the Russian Federation] (2019). Available at: https://arctic-russia. ru/project/skrytyy-ogon-vechnoy-merzloty/ (accessed 22 April 2021)

Tajmyrskij proryv: «Vostok Ojl» opredelit razvitie mirovoj neftegazovoj otrasli [Taimyr breakthrough: «Vostok Oil» will determine the development of the global oil and gas industry] (2020). Available at: Users/Admin/Desktop/2021 \%20Грант\%20c\%20КрасГАУ/Освоение\%20Арттики/На\%20 севере $\% 20$ Красноярского\%20края\%20дан\%20старт\%20проекту\%20_Восток\%20Ойл_\%20_\%20 Российская\%20газета.html (accessed 22 April 2021)

Vorob'eva, V.V. Esikova, T.N., Ionova, V.D., Malov, V. Yu. (2007). Nizhnee Priangar'e na novom etape osvoeniya: vozmozhnosti formirovaniya promyshlennyh klasterov [The Lower Angara Area at a new stage of development: the possibility of industrial clusters formation]. Novosibirsk, IEOPP, $78 \mathrm{p}$.

Zona operezhayushchego razvitiya - Nizhnee Priangar'e [The Lower Angara Area is advanced development zone] (2018). Available at: https://refdb.ru/look/2053265-pall.html (accessed 13 April 2021) 